\title{
Expert System for Diabetes Mellitus Detection and Handling Using Certainty Factor on Android-Based Mobile Device
}

\author{
R. Rizal Isnanto* \\ Faculty of Engineering, Diponegoro \\ University, Semarang, Indonesia \\ Dania Eridani \\ Faculty of Engineering, Diponegoro \\ University, Semarang, Indonesia \\ Sri S.Y. Wulandari Simbolon \\ Faculty of Engineering, Diponegoro \\ University, Semarang, Indonesia
}

\begin{abstract}
Diabetes Mellitus (DM) is a chronic disease that occurs when the pancreas cannot produce insulin. The expert system seeks to adopt human knowledge to solve problems, usually done by specialists or experts. Construction of expert system in this research using Expert System Development Life Cycle (ESDLC) methodology, Android operating system, Java programming languages, XML and database program using SQLite. The process of disease detection using the certainty factor method. By the certainty factor method, an accurate result obtained from calculations based on the weight of symptoms of the selected user can be provided. From test results, it can be concluded that the results of the application using the black-box method and direct testing by the expert, both the fault functions as well as the disease misdetection processes in the application are not found. This application can perform early disease detection following expert recommendation symptom data. The certainty factor method was successfully implemented in this DM expert system and can provide result a correct percentage of detection with the highest value of $90 \%$. The response on a questionnaire from users determines the validity of disease detection results.
\end{abstract}

Keywords: DM, expert system, android, certainty factor, insulin, chronic disease

Received: 07 May 2018; Accepted: 23 June 2018; Published: 13 July 2018

\section{INTRODUCTION}

DM is defined as a chronic disease or disorder with multiple etiologies characterized by high blood sugar levels with carbohydrate, lipid and protein metabolism disorders as a result of insulin function insufficiency [1]. According to website of ristekdikti.go.id, DM is still a serious health problem of the world, including Indonesia. Indonesia is ranked fourth with the highest prevalence of diabetes in the world after India, China and the United States [2]. Even the number of people with diabetes continues to increase from year to year, especially for type 2 DM. According to [3] among degenerative diseases, diabetes is one of the non-contagious diseases that will increase in the future [3].

The World Health Organization (WHO) makes an estimate that in 2000 the number of people with diabetes over the age of 20 is 150 million people and within 25 years later by 2025 , that number will swell to 300 million people [4]. DM is divided into four types, namely Type 1 Diabetes, Type 2 Diabetes, other types of DM, and Gestational Diabetes [5, 6]. However, besides the type of DM, there is also a condition called pre-diabetes.

In pre-diabetes, a patient's blood glucose level will be higher than normal, but not high enough to be diagnosed as DM [3]. Pre-diabetes may increase a person's risk of developing Type 2 Diabetes. The reason is when DM is

\footnotetext{
${ }^{*}$ Correspondence concerning this article should be addressed to R. Rizal Isnanto, Faculty of Engineering, Diponegoro University, Semarang, Indonesia. E-mail: rizal_isnanto@yahoo.com

(c) 2018 The Author(s). Published by KKG Publications. This is an Open Access article distributed under a Creative Commons AttributionNonCommercial-NoDerivatives 4.0 International License.
} 
not handled properly, it will cause chronic complications such as stroke, heart attack, peripheral nerve disorders, and amputation [7, 8, 9]. As a chronic disease, diabetes is associated with other disease complications. Collection of glucose in the bloodstream (hyperglycemia) causes other disease complications. However, these complications can be overcome by self-control management is done regularly and well. Self-control management of DM disease is a very important to do by patients since they can monitor their health. Self-control can be done with medication, diet, exercise, and monitoring blood sugar levels [10]. Die in patients purposes to lower sugar in the urine, to achieve normal weight, optimal nutritional status, and prevent diabetes complications [11, 12, 13].

In line with the current technological developments, many technologies are developed to utilize in the health field. One of the most widely used technologies in health is expert system. The expert system is a system that adopts human knowledge into computers, so that the computer can solve the problems commonly done by experts [14]. With expert systems, the general public can quickly identify the problem of the disease with accurate information that should only be resolved by an expert or an expert in the field.

Expert system are knowledge-based programs that provide solutions with expert knowledge standards to solve problems within a specific domain. Expert systems are also developed on the basis of knowledge and rules because the problems encountered are solved based on the expert's knowledge, rules, and experience [15]. Implementation of expert systems are widely used in health field. One of them is to detect a symptom or type of DM disease [16]. Expert system can also be used for medical consultations or diagnostic consultations. In this application, DM expert system is designed using Android Studio with Java programming language and SQLite database [17].

Nowadays expert system implementation has been widely used in the health field. The expert system is used as a storage of expert knowledge in computer programs so that decisions can be given with intelligent reasoning. One of the implementations of expert systems in the field of health is to diagnose symptoms of patients with DM [16]. One of diagnosis of DM symptoms can be analyzed using forward chaining method. The forward chaining method is a search method or forward-tracking technique that begins with existing information and the combination of rules to produce a conclusion and purpose, so that this method can be implemented to handle control or forecasting problems [15]. The expert system development in health can be applied in a mobile device application.
The use mobile devices application can also be used as a self-control management of DM patients [18]. The application can be implemented in various platforms like Android, iOS, as well as in Windows Phone.

Most number of mobile device applications are based on Android platform as a healthy control device [19]. The advantages of using an expert system are fast, cost saving, improved quality, save on working time, as well as have the reliable information [20].

The author designed an expert system application that will be able to detect DM that can run on the Android platform so that it can be used anytime and anywhere to detect whether a person suffering from DM so it can be treated appropriately.

\section{RESEARCH METHOD}

The research method used is ESDLC that has 6 stages, starting from the state assessment stage until the maintenance phase [21].

The first stage in system development is the state assessment stage. At this stage, the requirement analysis associated with problems DM disease was done. To acquire the data, the direct observation on the place become the object of research was done.

The second stage is the collection stage of knowledge. The collection of various knowledge on DM diseases is done at this stage. The result of this stage is the knowledge base of the expert system to be developed.

The third stage is the design stage. The description on how the working or work processes of the expert system to be made are done at this stage. The fourth stage is testing. At this stage a system test is conducted to ensure that the system is built in accordance with the design and needs.

The fifth stage is to evaluate the system. At this stage what is done is a review of the system whether it is necessary to add to the system or not. The last stage is maintenance. The purpose of this stage is to maintain the performance of the system has been built.

\section{A. System Design}

This application of DM expert system is designed using Android Studio with Java programming language and SQLite database. The stage of making system is done according to the system requirement.

\section{B. Work Process Design}

One of the stages in the design of work process is making a general description of the system requirements using data flow diagram. Fig. 1 shows the data flow diagram of the system. 
There are two processes that run in the system that is to detect and provide information about the disease. In the first process the disease detection has 3 data streams consisting of "Choice of Symptoms", "List of Symptoms", and "Detection Result". From the flow of data the sys- tem will display the symptoms to the user and then users choose the symptoms suffered. Furthermore, the system will process user-selected symptoms by matching data from data storage. As a result the system will give the "Results Detection" to the user.

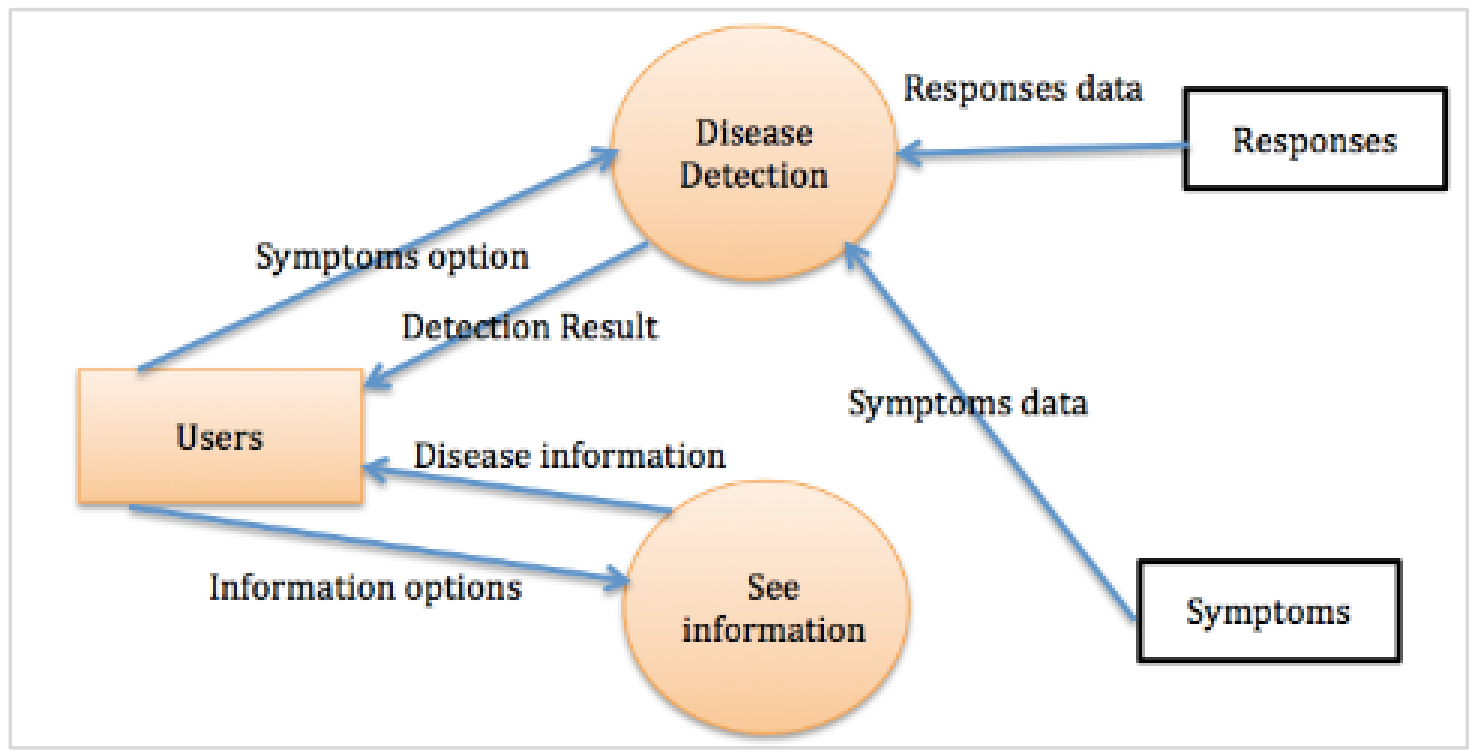

Fig. 1. Data flow diagram of the system

In the second process, i.e., looking at disease information, there are two data streams consisting of "Information Option" and "Disease Information". This process will occur if the user inputs what information you want to show in the app. The process on DFD Level 0 is then translated into a form of process specification used to describe all the data flow modeling process of the DM system application. Table 1 shows the DFD Level 0 specification table.

There are two things that are very influential in detecting DM disease apart from the symptoms, those are genetic factors and blood sugar levels. In this system will be used certainty factor method to show the size of certainty to a fact or rule. Table 2 shows the list of symptoms
[22].

The sequence of workings of the system is illustrated by a flow chart. The detection process starts after the user chooses the symptoms of the disease. The inserted symptoms will be processed and calculated percent confidence through the calculation of certainty factor. When the results of certainty factor certainty $10 \%-25 \%$ it will show the results of detection is Normal. Furthermore, when the calculation of certainty factor $26 \%-75 \%$ will be shown the results of detection of Pre-DM, and when the calculation of certainty factor $76 \%-90 \%$ then the result of the detection is DM. Fig. 2 shows the flow chart of the system. 
TABLE 1

PROCESS SPECIFICATION OF DFD LEVEL 0

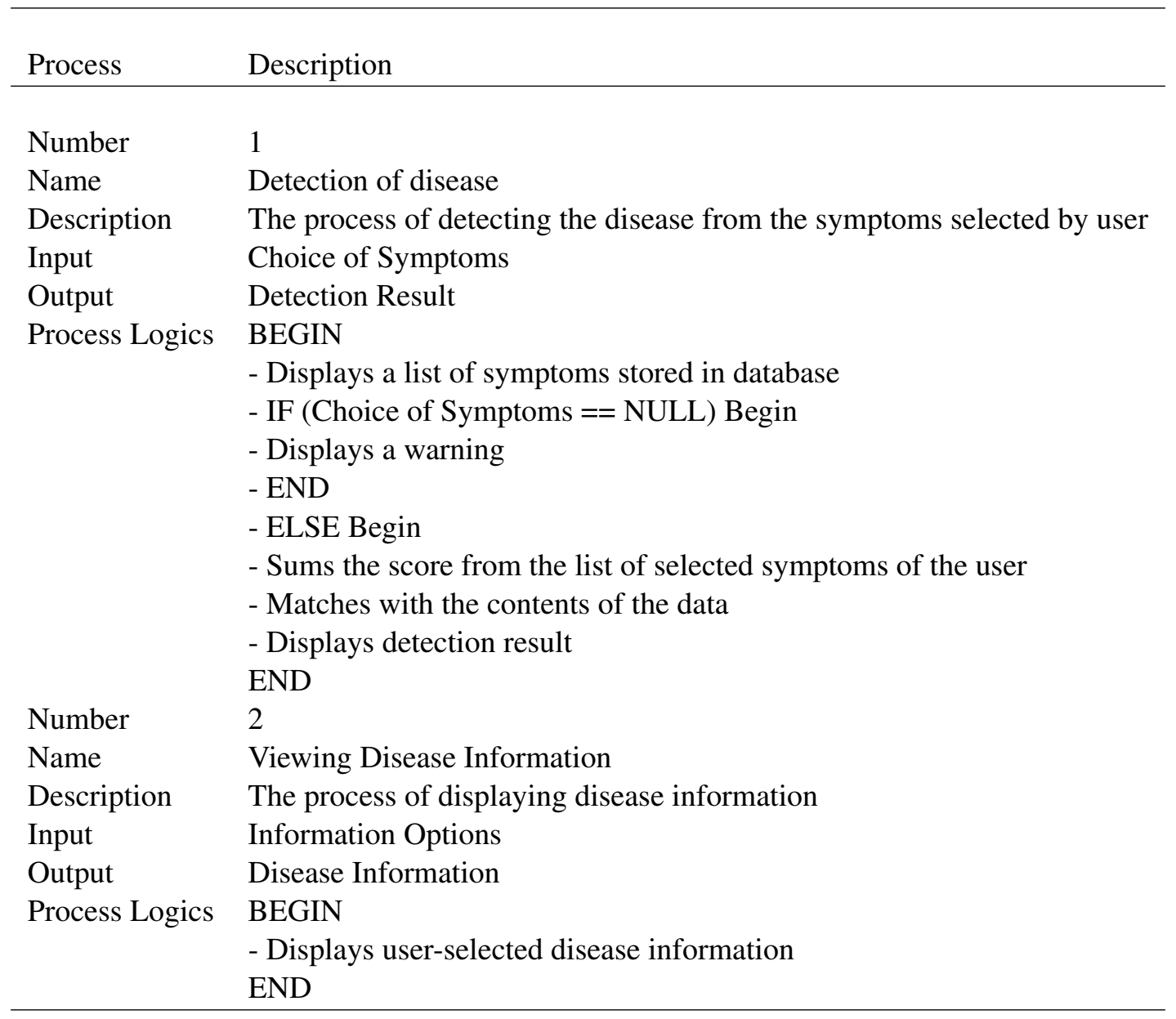

TABLE 2

LIST OF SYMPTOMS

Symptom Code Symptom Name

B01 Increased urine expenditure

B02 Increased thirst

B03 Increased hunger

B04 Fatigue and muscle weakness

B05 Increased infection rate

B06 Skin disorders: itching, boils

B07 excessive vaginal discharge (for women only)

B08 Tingling

B09 Weakness of the body

B10 Injuries or ulcers that do not heal

B11 In men sometimes complain of impotence (decreased production of sex hormones)

B12 Blurred eyes caused by cataracts

\section{Database Design}

The first step in the process of making the system is to create a database that contains expert knowledge base. Database design is done using SQLite. This database is used as a data storage medium. There are two tables made, namely the symptom table and also the response table. Table 3 shows the symptom table used in making this application. 
The symptom table contains three columns, namely the id_symptom column, symptom_name, gender, and groups. Id_symptom contains the id of each symptom and becomes the primary key or is the key of the table that makes the data has its own identity and distinguishes one from the other. The column symptom_name contains the questions for each symptom, the gender column con- tains the numbers 0.1 and 2, where for the questions that must appear when the user detects the number 0 , number 1 means that the question only appears when the user chooses a male gender and number 2 for female specific questions. The group column contains groups of symptoms that will be used to find the value of certainty factor. Table 4 shows the contents of the response table.

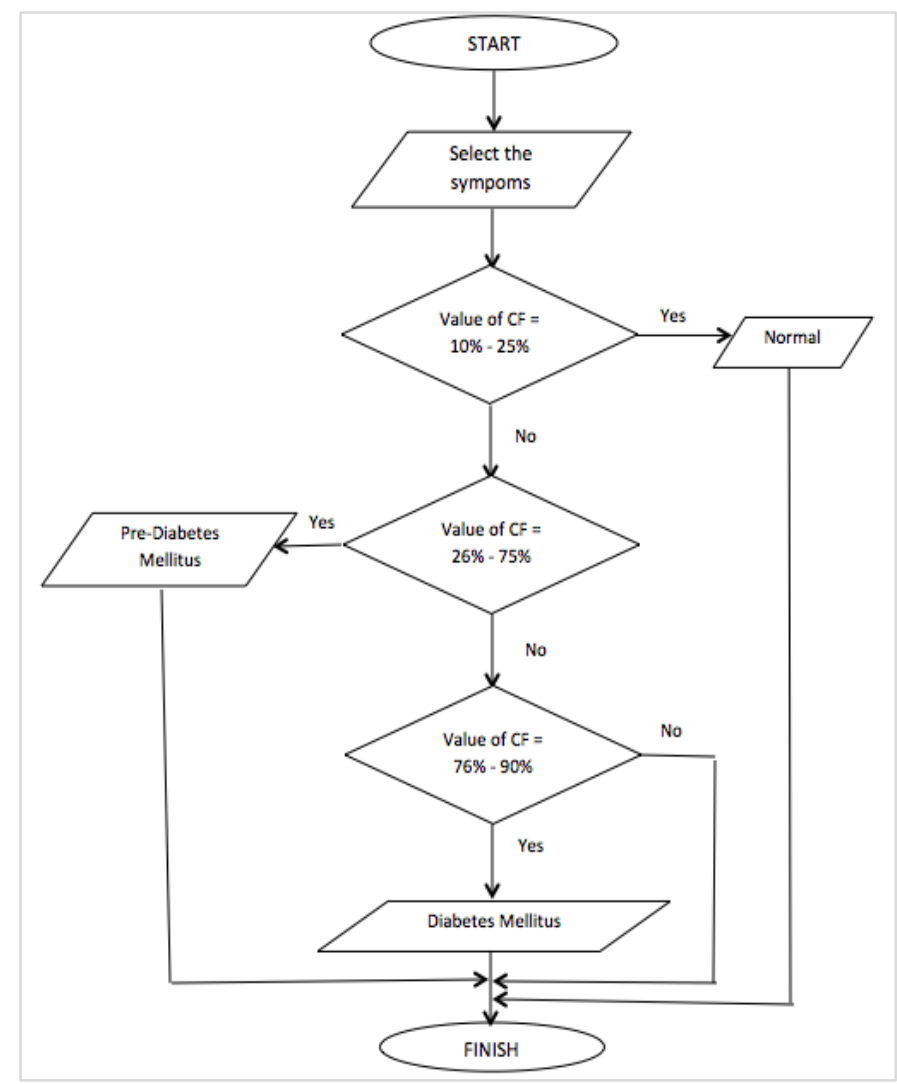

Fig. 2. Flowchart of application work process

TABLE 3

TABLE OF SYMPTOMS

\section{No id_symptom Symptom_name}

Gender cf_user

Are you from a family who has a history of DM or has DM?

When your body parts have an infection, how long can the infection heal? 
TABLE 4

RESPONSE TABLE

\begin{tabular}{lllll}
\hline \multicolumn{5}{c}{} \\
No & id_response & id_symptom & response & cf_user \\
\hline & & & & \\
1 & J01 & B01 & Yes & 0.9 \\
2 & J02 & B01 & No & 0.1 \\
3 & J03 & B02 & $1-4$ times a day & 0.1 \\
4 & J04 & B02 & 5 times a day & 0.3 \\
5 & J05 & B02 & 6 - 9 times a day & 0.5 \\
6 & J06 & B02 & 10 times a day & 0.7 \\
7 & J07 & B02 & 11 - 12 times a day & 0.9 \\
8 & J08 & B03 & 1 - 2 glass(es) a day & 0.1 \\
9 & J09 & B03 & 3 - 4 glasses a day & 0.3 \\
10 & J10 & B03 & $5-8$ glasses a day & 0.5 \\
11 & J11 & B03 & 9 - 10 glasses a day & 0.7 \\
12 & J12 & B03 & 11 - 15 glasses a day & 0.9 \\
13 & J13 & B03 & Once a day & 0.1 \\
14 & J14 & B04 & Twice a day & 0.3 \\
15 & J15 & B04 & 3 - 7 times a day & 0.5 \\
\hline
\end{tabular}

The answer table above contains four columns, namely the id_response, id_symptom, response, and cf_user columns. The primary key of the answer table is id_jwb. The answer column contains the answer to the symptom question, and the cf_user column contains the certainty factor value from the answer obtained from the expert. The answer table contains 65 answers, where for the first question using two answers, questions 2-13 use five answers for each question, and question 14 uses three answers. In this expert system detection results are divided into three, namely Normal, Pre-Diabetes, and DM.

\section{IMPLEMENTATION AND TESTING STAGE}

\section{A. Implementation}

In the implementation phase of the display interface of the previously designed application of expert DM system described at this stage. The Home page of the application is shown in Fig. 3.

In this page, there are two parts, those are the name of the application located at the top of the page and the application menu located in the middle of the page. There are three menus in this expert system application: the Start Detection menu, Disease Info menu, and the About Application menu. After Start Detection button selected, the Select Gender page appears which its design is shown in Fig. 4.

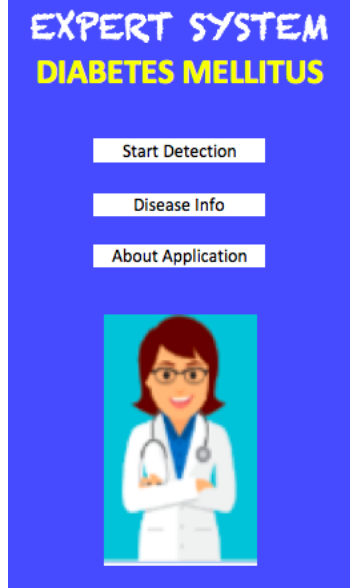

Fig. 3. Home page display

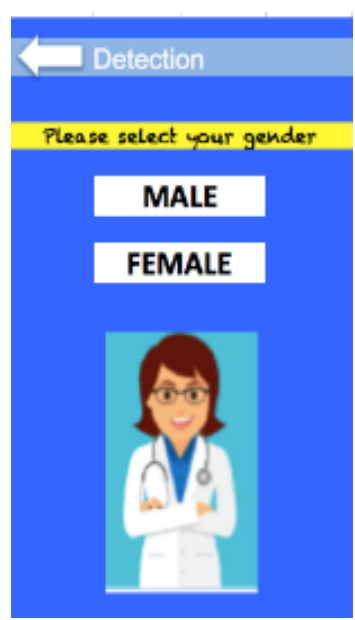

Fig. 4. Display of select_gender page 
The Start Detection page display is a page that displays questions from symptoms and on this page users are required to fill in the answers to each question. On this page the user must choose the gender first, because the question displayed will match the gender of the user. Once the user selects the gender then it will go to the page containing the symptom question. Fig. 5 shows a page that contains the question of symptoms.

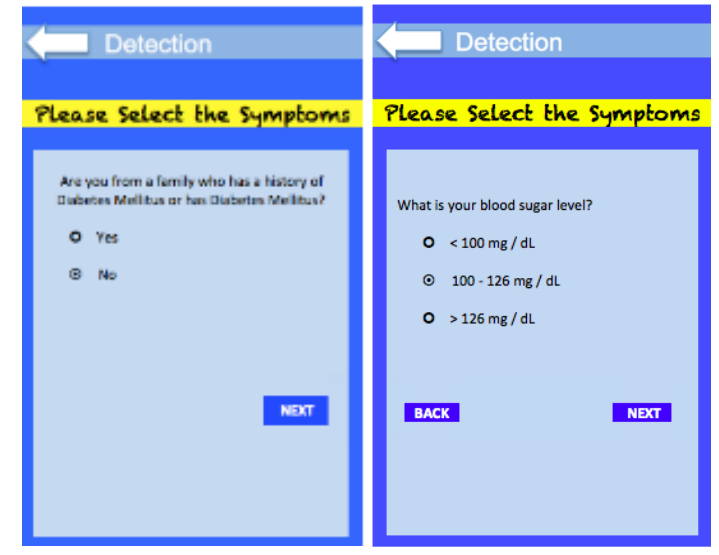

Fig. 5. Display of detection page

There are two buttons on the Detection Result page, the Next button, the Back button and the Detection Result button. When the user wants to proceed to the next question then the user must click the Next button, then when the user wants to return to the previous question and want to replace the answer then the user clicks Back button. Then after the user has finished answering all questions then clicking the Results button and the results of disease detection will appear according to the symptom question that has been selected as in Fig. 6 .

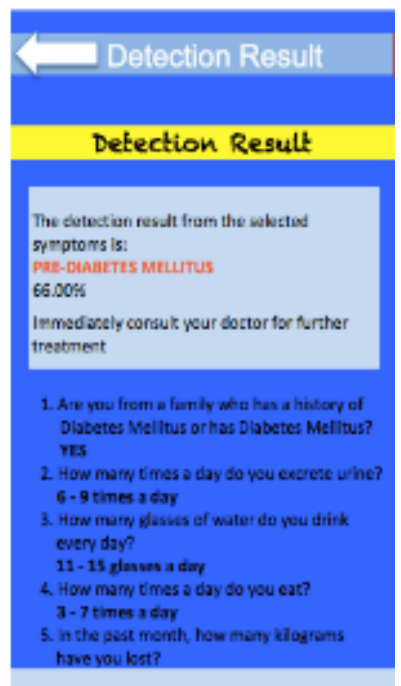

Fig. 6. Display of results page

Then on Disease Info page there are three menu choices that are DM Description, DM Symptoms, and DM Prevention. When the user selects the DM Description menu, the DM definition and classification will ap- pear. In the DM Symptoms menu option contains the types of DM symptoms that are often suffered by people with DM. While in the menu of DM Prevention contains tips for prevention and treatment of DM. Fig. 7 depicts a sample of DM Description page.

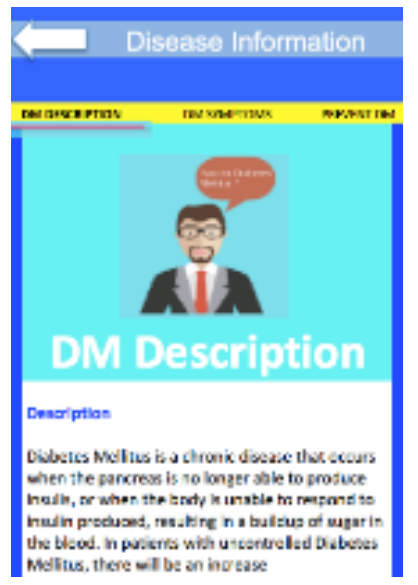

Fig. 7. A sample of display of DM description page

The last menu in this application is the About Application menu. The About Application page display contains an explanation of the DM expert system application and application developer data. Fig. 8 shows the About Application page.

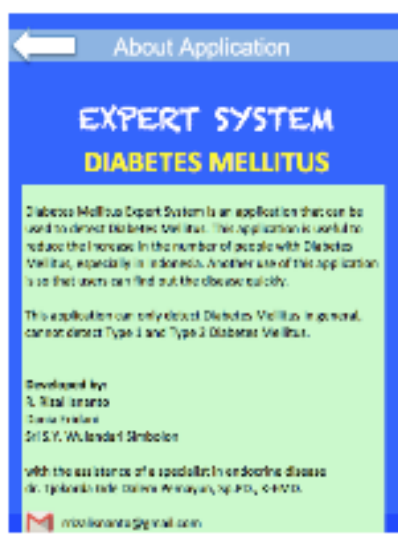

Fig. 8. Display of about application page

\section{B. $\quad$ System Testing}

Application testing is done using the black box method. From the test it can be shown that the application is already running in accordance with the desired result, as shown in Table 5 which shows the functional test results.

The application testing using the black box method indicates that the application is running in accordance with the desired results. As shown in Table 3 which displays the results of the "Succeed" application test in each action.

On the other hand, the results of tests conducted by experts indicate that the symptoms entered when testing 
and the resulting detection results are appropriate. It can be shown that the questions that must be answered and the results obtained when the user detects the disease. Symptom questions displayed on the application are in accordance with expert knowledge. On the Detection Results page there are symptoms selected, which then displays the results of disease detection with $50 \%$ certainty factor percentage.

TABLE 5

FUNCTIONAL TESTING

\begin{tabular}{|c|c|c|c|}
\hline Testing & Action & Desired Result & Result \\
\hline Menu Home & $\begin{array}{l}\text { Accessing the initial page of appli- } \\
\text { cation }\end{array}$ & $\begin{array}{l}\text { Displaying the start page that con- } \\
\text { tains three menus and application } \\
\text { names. }\end{array}$ & Succeed \\
\hline Detection start menu & $\begin{array}{l}\text { Accessing the detection page by } \\
\text { clicking the Start Detection button } \\
\text { on the Home menu }\end{array}$ & $\begin{array}{l}\text { Displaying the choices of gender and } \\
\text { symptoms of DM selected by the } \\
\text { user }\end{array}$ & Succeed \\
\hline $\begin{array}{l}\text { Male button on the Start } \\
\text { Detection page }\end{array}$ & $\begin{array}{l}\text { Clicking the Male button on the Start } \\
\text { Detection page }\end{array}$ & $\begin{array}{l}\text { Displaying questions and choices of } \\
\text { answers to the symptoms of DM se- } \\
\text { lected by the user }\end{array}$ & Succeed \\
\hline $\begin{array}{l}\text { Female button on the Start } \\
\text { Detection page }\end{array}$ & $\begin{array}{l}\text { Clicking the Female button on the } \\
\text { Start Detection page }\end{array}$ & $\begin{array}{l}\text { Displaying questions and choices of } \\
\text { answers to the symptoms of DM se- } \\
\text { lected by the user }\end{array}$ & Succeed \\
\hline $\begin{array}{l}\text { The Answer Options but- } \\
\text { ton on the Start Detection } \\
\text { page }\end{array}$ & $\begin{array}{l}\text { Clicking the Answer Options button } \\
\text { on the symptom question }\end{array}$ & $\begin{array}{l}\text { To save the selected answer and pro- } \\
\text { ceed to the next question. }\end{array}$ & Succeed \\
\hline $\begin{array}{l}\text { The Next button on the } \\
\text { Start Detection page }\end{array}$ & $\begin{array}{l}\text { Clicking the Next button on the } \\
\text { symptom question }\end{array}$ & Displays the next symptom question. & Succeed \\
\hline $\begin{array}{l}\text { Next button on the Start } \\
\text { Detection page }\end{array}$ & $\begin{array}{l}\text { Clicking the Next button after the } \\
\text { user has selected the answer to the } \\
\text { symptom question }\end{array}$ & Displays the next symptom question. & Succeed \\
\hline $\begin{array}{l}\text { Back button on the Start } \\
\text { Detection page }\end{array}$ & $\begin{array}{l}\text { Clicking the Back button after the } \\
\text { user has selected the answer to the } \\
\text { symptom question }\end{array}$ & $\begin{array}{l}\text { Displays the previous symptom } \\
\text { question. }\end{array}$ & Succeed \\
\hline $\begin{array}{l}\text { Result button on the Start } \\
\text { Detection page }\end{array}$ & $\begin{array}{l}\text { Click the Result button after the user } \\
\text { answers all symptom questions }\end{array}$ & $\begin{array}{l}\text { Displays the result of detection from } \\
\text { the selected symptoms }\end{array}$ & Succeed \\
\hline Disease Info Menu & $\begin{array}{l}\text { Access the Disease Info page by } \\
\text { clicking the Disease Info button on } \\
\text { the Home menu }\end{array}$ & $\begin{array}{l}\text { Displays a page with three menu } \\
\text { options, i.e., DM Description, DM } \\
\text { Symptoms, and DM Prevention }\end{array}$ & Succeed \\
\hline Description DM Menu & $\begin{array}{l}\text { Select the DM Description menu op- } \\
\text { tion on the Disease Info page }\end{array}$ & $\begin{array}{l}\text { Displays the DM description page } \\
\text { which contains the definition and } \\
\text { classification of DM }\end{array}$ & Succeed \\
\hline DM Symptoms Menu & $\begin{array}{l}\text { Select the DM Symptoms menu op- } \\
\text { tion on the Disease Info page }\end{array}$ & $\begin{array}{l}\text { Displays the DM Symptoms page } \\
\text { that contains symptoms of DM }\end{array}$ & Succeed \\
\hline About Application Menu & $\begin{array}{l}\text { Access the About Applications page } \\
\text { by clicking the About Application } \\
\text { button on the Home menu }\end{array}$ & $\begin{array}{l}\text { Displays the About Application } \\
\text { page that contains the application de- } \\
\text { scription and application developer. }\end{array}$ & Succeed \\
\hline $\begin{array}{l}\text { Result button on the Start } \\
\text { Detection page }\end{array}$ & $\begin{array}{l}\text { Click the Result button after the user } \\
\text { answers all symptom questions }\end{array}$ & $\begin{array}{l}\text { Displays the result of detection from } \\
\text { the selected symptoms }\end{array}$ & Succeed \\
\hline
\end{tabular}


The result of certainty factor percentage calculation begins with giving a Confidence Value (CF) for each fact of the patient's answer and symptoms by the expert. In the first symptom question, there are only 2 answer choices, "Yes" or "No". When the user chooses "Yes" then CF user $=0.9$, and if the user chooses "No" then the user $\mathrm{CF}$
$=0.1$. In the last symptom question, 3 (three) choices of answer is given. Each of which has a CF weight as depicted in Table 6.

Furthermore, for symptom questions 2-12, five answer choices are given with each CF weighted as shown in Table 7.

TABLE 6

WEIGHTS OF 3 (THREE) CHOICES OF ANSWER

\begin{tabular}{ll} 
Choices & Weight \\
\hline & \\
1 & 0.1 \\
2 & 0.5 \\
3 & 0.9 \\
\hline
\end{tabular}

TABLE 7

WEIGHTS OF 5 (FIVE) CHOICES OF ANSWER

\begin{tabular}{ll} 
Choices & Weight \\
\hline & \\
1 & 0.1 \\
2 & 0.3 \\
3 & 0.5 \\
4 & 0.7 \\
5 & 0.9 \\
\hline
\end{tabular}

The process of calculating the certainty factor percentage is done using the sequential CF formula. Sequential $\mathrm{CF}$ is obtained from the calculation of the combination of rules of all premises in one rule with CF given by experts. The following is testing the calculation of certainty factor in the application using manual calculations to determine the suitability of the calculation results on the system with the results of manual calculations.

For example, Table 8 shows the expert answers from 13 symptom questions in this application with CFusers values based on answer choices.

TABLE 8

EXPERT ANSWERS FROM 13 SYMPTOM QUESTIONS

\begin{tabular}{llc}
\hline & & \\
No. & Symptom Names & CF $_{\text {Users }}$ \\
\hline & & \\
1. & Heredity factor & 0.9 \\
2. & Increased urine excretion & 0.5 \\
3. & Increased thirst & 0.5 \\
4. & Increased hunger & 0.5 \\
5. & Fatigue and muscle weakness & 0.1 \\
6. & Increased infection rate & 0.7 \\
7. & Itching, boils & 0.3 \\
8. & Tingling & 0.7 \\
9. & Body weakness & 0.7 \\
10. & Wounds and boils that do not heal & 0.9 \\
11. & Blurred eyes caused by cataracts & 0.7 \\
12. & Excess leucorrhoea (specifically for women) or decreased production of sexual & 0.7 \\
& hormones (especially for men) & \\
13. & Blood sugar level & 0.5 \\
\hline
\end{tabular}


The next step is to give CF experts for each of the following facts and symptoms:

1. Symptom 1 (heredity factor)

CFexpert : 0.4

2. Symptom 2 (Increased urine expenditure) AND

Symptom 3 (Increased thirst) AND

Symptom 4 (Increased hunger) AND

Symptom 5 (Fatigue and muscle weakness)

CFexpert : 0.4

3. Symptom 6 (increased infection rate) AND

Symptom 7 (itching, boils) AND

Symptom 8 (tingling) AND

Symptom 9 (body weakness)

CFexpert : 0,05

4. Symptom 10 (Wounds and boils that do not heal) AND

Symptom 11 (Blurred eyes caused by cataracts) AND

Symptom 12 (excessive vaginal discharge for women or decreased production of sexual hormones for men)

CFexpert : 0,05

5. Symptom 13 (Blood sugar level)

CFexpert : 0,1

The next step is to calculate the combination of rules from CFusers then calculating CFsequential between CFexpert and CFusers. The combination of rules used in this calculation is as follows.

$$
F a c t(E 1 \mathrm{AND} E 2)=\min [C F(H, E 1), C F(H, E 2)
$$

For the fact of (Symptom 1 AND Symptom 13), its se- quential CF can be directly calculated because it stands alone. However, for other symptoms, their sequential CFs can be obtained by rules combination.

1. CFsequential 1 (Symptom 1$)=0.4 * 0.9=0.36$

2. Symptom 2, Symptom 3, Symptom 4, Symptom 5 $=\min [$ Symptom 2, Symptom 3, Symptom 4, Symptom $5]=\min [0.5 ; 0.5 ; 0.5 ; 0.1]=0.1$

CFsequential $2=0,4 * 0,1=0,04$

3. Symptom 6, Symptom 7, Symptom 8, Symptom 9 $=\min [$ Symptom 6, Symptom 7, Symptom 8, Symptom 9] $=\min [0.7 ; 0.3 ; 0.7 ; 0.7]=0.3$

CFsequential $3=0.05 * 0.3=0.015$

4. Symptom 10, Symptom 11, Symptom $12=\min$ [Symptom 10, Symptom 11, Symptom 12] $=\min [0.9$; $0.7 ; 0.7]=0.7$

CFsequential $4=0.05 * 0.7=0.035$

5. CFsequential $5($ Symptom 13$)=0.1 * 0.5=0.05$

Therefore, Total CF from the answers above can be determined as follows.

CFtotal $=$ CFsequential $1+$ CFsequential $2+$ CFse quential $3+$ CFsequential $4+$ CFsequential 5

$=0.36+0.04+0.015+0.035+0.05$

$=0.5 * 100 \%$

$=50 \%$.

Based on the above manual calculation, it can be seen that the manual calculation is similar with the certainty factor calculation as result from application.

Table 9 depicts the comparison between manual and application calculation results.

TABLE 9

COMPARISON BETWEEN MANUAL CALCULATION AND APPLICATION CALCULATION RESULTS

Manual calculation Application calculation

\begin{tabular}{lll} 
Percentage of CF & $50 \%$ & $50 \%$ \\
Detection result & Pre-DM & Pre-DM \\
\hline
\end{tabular}

While in how to handle the DM, the application provides some tips for prevention and treatment of DM, which included in DM Prevention menu.

\section{CONCLUSION AND SUGGESTIONS}

Based on the results of testing and analysis of the application, it can be concluded as follows. The application can detect disease early according to symptom data from expert recommendations. The certainty factor method has been successfully implemented in the DM Expert System and can provide results in the form of a percentage of confidence in the accuracy of detection with the highest percentage value of $90 \%$. Answers from users determine the validity of disease detection results. If the user wants to get valid results, the user is expected to check blood sugar levels first so that they can answer some questions related to blood sugar levels. The black box test results indicate that the system is running well and has no errors in performing the function.

While in how to handle the DM, the application provides some tips for prevention and treatment of DM, which included in DM Prevention menu.

Based on the results of testing of the DM Expert System application that has been developed, there are several suggestions as follows. This expert system can be further developed to detect DM type 1, DM type 2, gestational di- 
abetes and other types of diabetes. This expert system can be further developed for iOS mobile devices so that more and more smartphone users can use this expert system application.

\section{ACKNOWLEDGEMENT}

We acknowledge with thanks to Department of Computer Engineering, Faculty of Engineering, Diponegoro University - for their financial grant to this Fundamental Research in 2018 for which this paper can be published.

\section{REFERENCES}

[1] S. E. Taylor, Health Psychology. New York, NY: Tata McGraw-Hill Education, 2006.

[2] R. B. Pramono. (2016) 60 percent of Indonesian people are unaware of diabetes. [Online]. Available: https://bit.ly/2JQc7hB

[3] A. W. Sudoyo, B. Setiyohadi, I. Alwi, M. Simadibrata, and S. Setiati, Internal Medicine. Jakarta, Indonesia: Interna Publishing, 2009.

[4] S. Candra, "Expert system for determining healthy food menu for mobile-based diabetes mellitus patients," Jurnal Sistem dan Teknologi Informasi, vol. 2, no. 2, pp. 104-109, 2014.

[5] Diabetes Quebec. (2018) Types of diabetes. [Online]. Available: https://bit.ly/2YBaBEf

[6] American Diabetes Association, "Classification and diagnosis of diabetes: Standards of medical care in diabetes2018," Diabetes Care, vol. 41, pp. S13-S27, 2018. doi: https://doi.org/10.2337/dc18-S002

[7] B. C. Saputro, R. Delima, and J. Purwadi, "Diabetes mellitus diagnosis system using the certainty factor method," Jurnal Informatika, vol. 7, no. 1, pp. 1-13, 2011. doi: https://doi.org/10.21460/inf.2011.71.92

[8] K. Prabsangob, "Relationships of health literacy diabetes knowledge and social support to self-care behavior among type 2 diabetic patients," International Journal of Health and Medical Sciences, vol. 2, no. 3, pp. 68-72, 2016. doi: https://doi.org/ 10.20469/ijhms.2.30005-3

[9] T. Sungkhapong, P. Prommete, N. Martkoksoong, and B. Kittichottipanich, "The health behaviors modification for controlling and prevention of diabetes mellitus by using promise model at premruthai pravate community Bangkok," Journal of Advances in Health and Medical Sciences, vol. 2, no. 3, pp. 97-101, 2016. doi: https://doi.org/10.20474/jahms2. 3.3

[10] R. E. Glasgow and P. A. Nutting, Diabetes. New York, NY: Oxford University Press, 2004.
[11] Y. Primanda, C. Kritpracha, and P. Thaniwattananon, "Dietary behaviors among patients with type 2 diabetes mellitus in Yogyakarta, Indonesia," Nurse Media Journal of Nursing, vol. 1, no. 2, pp. 211-223, 2011.

[12] A. B. Evert et al., "Nutrition therapy recommendations for the management of adults with diabetes," Diabetes Care, vol. 37, pp. S120-S143, 2014.

[13] A. Irianton, Nutrition Care Management. Yogyakarta, Indonesia: Universitas Gajah Mada Yogyakarta, 2013.

[14] Y. P. Bria and E. A. S. Takung, "Web-based dengue diagnosis and tuberculosis expert system development using the certainty factor method," in National Seminar on Information and Communication Technology, Yogyakarta, Indonesia, 2015.

[15] J. C. G. G. D. Riley, Expert Systems: Principle and Programming. Boston, MA: Thomson Course Technology, 2004.

[16] R. Meza-Palacios, A. A. Aguilar-Lasserre, E. L. Urena-Bogarin, C. F. Vazquez-Rodriguez, R. Posada-Gomez, and A. Trujillo-Mata, "Development of a fuzzy expert system for the nephropathy control assessment in patients with type 2 diabetes mellitus," Expert Systems with Applications, vol. 72, pp. 335-343, 2017. doi: https://doi.org/10.1016/j.eswa.2016.10.053

[17] F. Rasjid. (2017) Android: Operating system on a smartphone. [Online]. Available: http://www.ubaya.ac.id

[18] L. Medsker, A. J. La Salle, and D. Hillmer, "Knowledge acquisition and the expert system life cycle," in IEEE Conference on Managing Expert System Programs and Projects, Bethesda, MD, 1990. doi: 10.1109/MESPP.1990.122711

[19] F. Başçiftçi and Ö. F. Hatay, "Reduced-rule based expert system by the simplification of logic functions for the diagnosis of diabetes," Computers in Biology and Medicine, vol. 41, no. 6, pp. 350-356, 2011. doi: https://doi.org/10.1016/j.compbiomed. 2011.03.012

[20] P. P. Brzan, E. Rotman, M. Pajnkihar, and P. Klanjsek, "Mobile applications for control and self management of diabetes: A systematic review," Journal of Medical Systems, vol. 40, no. 9, pp. 1-10, 2016. doi: https://doi.org/10.1007/s10916-016-0564-8

[21] M. Furmankiewicz, J. Furmankiewicz, and P. Ziuziański, "Evaluation of the expert system as a stage of the life cycle model ESDLC on the example of WIKex," Computer Science and Mathe- 
matical Modelling, vol. 2, no. 2, pp. 23-32, 2015. doi: https://doi.org/10.5604/15084183.1197448

[22] E. Qanita. (2011) Consensus on the management of prevention of type 2 diabetes mellitus in Indonesia. [Online]. Available: https://bit.ly/2M5WF3A 